\title{
Impact of a Smarter Lunchroom intervention on food selection and consumption among adolescents and young adults with intellectual and developmental disabilities in a residential school setting
}

\author{
Kristie L Hubbard ${ }^{1, *}$, Linda G Bandini ${ }^{2,3}$, Sara C Folta ${ }^{1}$, Brian Wansink ${ }^{4}$, Misha \\ Eliasziw ${ }^{5}$ and Aviva Must ${ }^{5}$ \\ ${ }^{1}$ Friedman School of Nutrition Science and Policy, Tufts University, 150 Harrison Avenue, Boston, MA 02111 , \\ USA: ${ }^{2}$ Eunice Kennedy Shriver Center, University of Massachusetts Medical School, Waltham, MA, USA: \\ ${ }^{3}$ Department of Health Sciences, Boston University, Boston, MA, USA: ${ }^{4}$ Dyson School of Applied Economics and \\ Management, Cornell University, lthaca, NY, USA: ${ }^{5}$ Department of Public Health and Community Medicine, Tufts \\ University School of Medicine, Boston, MA, USA
}

Submitted 19 April 2013: Final revision received 18 November 2013: Accepted 4 February 2014: First published online 17 March 2014

\begin{abstract}
Objective: To assess whether a Smarter Lunchroom intervention based on behavioural economics and adapted for students with intellectual and developmental disabilities would increase the selection and consumption of fruits, vegetables and whole grains, and reduce the selection and consumption of refined grains.

Design: The 3-month intervention took place at a residential school between March and June 2012. The evaluation employed a quasi-experimental, pre-post design comparing five matched days of dietary data. Selection and plate waste of foods at lunch were assessed using digital photography. Consumption was estimated from plate waste.

Setting: Massachusetts, USA.

Subjects: Students ( $n$ 43) aged 11-22 years with intellectual and developmental disabilities attending a residential school.

Results: Daily selection of whole grains increased by a mean of 0.44 servings (baseline 1.62 servings, $P=0.005$ ) and refined grains decreased by a mean of 0.33 servings (baseline 0.82 servings, $P=0 \cdot 005$ ). The daily consumption of fruits increased by a mean of 0.18 servings (baseline 0.39 servings, $P=0 \cdot 008$ ), whole grains increased by 0.38 servings (baseline 1.44 servings, $P=0.008$ ) and refined grains decreased by a mean of 0.31 servings (baseline 0.68 servings, $P=0.004$ ). Total kilojoules and total gram weight of food selected and consumed were unchanged. Fruit $(P=0 \cdot 04)$ and vegetable $(P=0 \cdot 03)$ plate waste decreased.

Conclusions: A Smarter Lunchroom intervention significantly increased whole grain selection and consumption, reduced refined grain selection and consumption, increased fruit consumption, and reduced fruit and vegetable plate waste. Nudge approaches may be effective for improving the food selection and consumption habits of adolescents and young adults with intellectual and developmental disabilities.
\end{abstract}

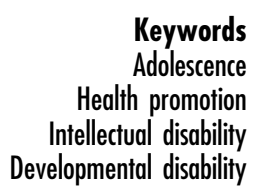

Keywords

Health promotion Developmental disability
Population-based data from the $\mathrm{USA}^{(1-3)}$ and Australia ${ }^{(4)}$ indicate that youth with intellectual and developmental disabilities (I/DD) are at an increased risk of obesity. A higher prevalence of obesity has been reported among non-representative samples of youth with spina bifida ${ }^{(5)}$, cerebral palsy ${ }^{(6,7)}$, Down's syndrome ${ }^{(8)}$ and intellectual disability $^{(9-12)}$. Obesity among youth with I/DD may undermine their ability to live independently, limit future opportunities for employment, and may contribute to health disparities in adulthood ${ }^{(13)}$.
Youth with I/DD are more vulnerable to poor diet quality compared with typically developing children due to their complex medical, physical and behavioural challenges (i.e. medication use, cognitive impairments, eating problems $)^{(14-16)}$. Compared with typically developing peers, youth with I/DD, including children with autism spectrum disorder, consume fewer daily servings of fruits and vegetables $^{(17,18)}$ and these outcomes have a positive association with lower family income ${ }^{(18)}$. Schools represent ideal environments for public health interventions to 
improve population-level dietary patterns of children and adolescents $^{(19)}$. Little is known about the extent to which youth with I/DD have been included in school-based efforts to improve dietary intake ${ }^{(20)}$.

Behavioural economics and principles of behavioural science that guide recent efforts to 'steer students to better choices by making low or no-cost changes to the cafeteria environment' are termed the Smarter Lunchroom Movement. When redesigning lunchrooms to be smarter, how food is served and presented to students is modified rather than emphasizing extreme changes to what foods are served ${ }^{(21)}$. This approach preserves autonomous choice - a central tenet of health promotion for youth with I/DD ${ }^{(22)}$. The six principles of Smarter Lunchroom design include efforts to: (i) manage portion sizes; (ii) make healthy choices more convenient; (iii) improve visibility of healthier foods; (iv) enhance taste expectations; (v) utilize suggestive selling (prompts); and (vi) use smart pricing and bundling strategies ${ }^{(23)}$. Smarter Lunchroom interventions have improved fruit and vegetable selection and consumption among typically developing high-school students ${ }^{(24)}$, but these strategies have not been tested specifically among youth with I/DD. Furthermore, no published research has addressed whether youth with I/DD in residential education settings can benefit from adaptations to evidenced-based health promotion strategies that have proved successful among typically developing youth in regular education settings.

The present study adapted these Smarter Lunchroom principles to meet the needs of students with I/DD enrolled in a residential school. Outcomes of interest, established a priori, aligned with new federal nutrition standards for school lunch ${ }^{(25)}$, addressed dietary deficits common among youth, and included improvements in the selection and consumption of fruits, vegetables, whole grains and refined grains based on the number of servings. The evaluation employed a pre-post quasiexperimental design in which five days of matched dietary data were compared between baseline and follow-up to assess changes at the individual level ${ }^{(26)}$. We hypothesized that the intervention would increase students' selection and consumption of fruits, vegetables and whole grains, and decrease their selection and consumption of refined grains, over a 3-month period.

\section{Methods}

\section{Setting}

Of the 6.5 million students with disabilities served through the Individuals with Disabilities Education Act (IDEA) in the USA, $3 \cdot 4 \%$ are served in private specialized day and/or residential programmes (2008 data) ${ }^{(27)}$. Under IDEA, the right to a free and public education in the 'least restrictive environment' provides that separate schooling in private programmes occurs only when the nature or severity of the disability is such that education in regular classes cannot be achieved satisfactorily. The intervention was implemented in Massachusetts at a private specialized residential school for students with I/DD between December 2011 and June 2012. The school served 120 students aged 9-22 years with I/DD and a range of secondary emotional, mental health and behavioural conditions including autism spectrum disorder. Eighty-eight students lived at the school (i.e. residential) and thirty-two attended the day programme only. Eighty per cent of students' families were at or below the federal poverty level. Students aged 9-18 years were enrolled in the education programme and grouped into classrooms by age and functional ability; students aged 18-22 were enrolled in the vocation programme to focus on job training and grouped according to job site. The student to teacher ratio was 3 to 1.

\section{Recruitment}

The study was conducted according to the guidelines established in the Declaration of Helsinki and all procedures involving human subjects were approved by the Tufts University Institutional Review Board. At the school administrators' request, all students participated in the intervention to avoid disruptions in daily routines. The research aspect was limited to the pre-post evaluation of the selection and plate waste of foods at lunch using digital photography. The licensing policy of the school stipulated students classified as wards of the state ( $n$ 20) were ineligible to participate in the research aspects of the intervention. Recruitment letters were sent to the families of the remaining eligible students ( $n$ 100). Written parental permission to participate in the research aspect (evaluation) was received for fifty-one students. Assent to participate in the evaluation was obtained from participants via classroom visits. Participants were told that pictures would be taken of their tray before and after they ate lunch to help us learn more about students' eating habits. Participants were aware that they could stop participating at any time and were free to decline having the food photographs taken of their lunch tray on each day of data collection.

\section{Baseline conditions}

Formative research was conducted between December 2011 and February 2012 and is described elsewhere ${ }^{(28)}$. Baseline data were collected in February 2012 prior to any dining hall layout changes. The school participated in the School Breakfast and National School Lunch Programs, with breakfast and dinner provided in the residential housing units. The intervention focused on the lunch meal, served daily in the dining hall from 10.45 to 12.00 hours. School food service followed a seasonal three-week cycle menu. Table 1 displays week 1 of the baseline menu. The order of choices in the serving line at baseline was as follows: (i) peanut butter and jelly 
Table 1 Menu at baseline

\begin{tabular}{|c|c|c|c|c|c|}
\hline & Monday & Tuesday & Wednesday & Thursday & Friday \\
\hline \multicolumn{6}{|l|}{ Entrée 1 with bundled side } \\
\hline Entrée & Asian chicken salad & $\begin{array}{l}\text { Veggie burger on whole-wheat } \\
\text { bun }\end{array}$ & $\begin{array}{l}\text { Steak and blue cheese salad } \\
\text { with whole-wheat roll }\end{array}$ & $\begin{array}{l}\text { Sausage gumbo over brown } \\
\text { rice }\end{array}$ & $\begin{array}{l}\text { Tuna caprese salad with } \\
\text { flatbread crackers }\end{array}$ \\
\hline Bundled side dish & & $\begin{array}{l}\text { Mediterranean mix (tomatoes, } \\
\text { cucumbers, feta cheese) }\end{array}$ & & & \\
\hline \multicolumn{6}{|l|}{ Entrée 2 with bundled side } \\
\hline Entrée & $\begin{array}{l}\text { Grilled mozzarella cheese } \\
\text { sandwich on whole-wheat } \\
\text { bread }\end{array}$ & $\begin{array}{l}\text { Barbeque turkey tips with corn } \\
\text { bread }\end{array}$ & Popcorn chicken & $\begin{array}{l}\text { Roasted turkey wrap with } \\
\text { spinach and tomato }\end{array}$ & Pizza on whole-grain crust \\
\hline Bundled side dish & Baby carrots & $\begin{array}{l}\text { Baby spinach side salad with } \\
\text { cucumbers and grape } \\
\text { tomatoes }\end{array}$ & $\begin{array}{l}\text { Cucumbers and carrots with } \\
\text { dip }\end{array}$ & Whole grain goldfish & Garden greens side salad \\
\hline Soup & $\begin{array}{l}\text { Turkey wild rice cranberry } \\
\text { soup }\end{array}$ & Vegetable soup & Tuscan soup & $\begin{array}{l}\text { Chicken noodle Florentine } \\
\text { soup }\end{array}$ & $\begin{array}{l}\text { Roasted garlic rosemary } \\
\text { chowder }\end{array}$ \\
\hline Dessert & $\begin{array}{l}\text { Chocolate pudding with } \\
\text { whipped topping }\end{array}$ & & $\begin{array}{l}\text { Yellow cake with chocolate } \\
\text { frosting }\end{array}$ & Homemade trail-mix & \\
\hline Canned fruit & & Canned peaches & & & Fruit cocktail \\
\hline \multirow{3}{*}{ Whole fresh fruit } & Apples & Apples & Apples & Apples & Apples \\
\hline & Bananas & Bananas & Bananas & Bananas & Bananas \\
\hline & Oranges & Oranges & Oranges & Oranges & Oranges \\
\hline Yoghurt & 4 oz low-fat & 4 oz low-fat & 4 oz low-fat & 4 oz low-fat & 4 oz low-fat \\
\hline Milk & $\begin{array}{l}\text { Skimmed, } 1 \% \text {, Lactaid (white } \\
\text { only) }\end{array}$ & $\begin{array}{l}\text { Skimmed, } 1 \% \text {, Lactaid (white } \\
\text { only) }\end{array}$ & $\begin{array}{l}\text { Skimmed, } 1 \% \text {, Lactaid (white } \\
\text { only) }\end{array}$ & $\begin{array}{l}\text { Skimmed, } 1 \% \text {, Lactaid (white } \\
\text { only) }\end{array}$ & $\begin{array}{l}\text { Skimmed, } 1 \% \text {, Lactaid } \\
\text { (white only) }\end{array}$ \\
\hline $\begin{array}{l}\text { Alternative entrée with } \\
\text { bundled side dish }\end{array}$ & $\begin{array}{l}\text { Peanut butter and jelly } \\
\text { sandwich on white bread } \\
\text { with side of pretzels }\end{array}$ & $\begin{array}{l}\text { Peanut butter and jelly } \\
\text { sandwich on white bread } \\
\text { with side of pretzels }\end{array}$ & $\begin{array}{l}\text { Peanut butter and jelly } \\
\text { sandwich on white bread } \\
\text { with side of pretzels }\end{array}$ & $\begin{array}{l}\text { Peanut butter and jelly } \\
\text { sandwich on white bread } \\
\text { with side of pretzels }\end{array}$ & $\begin{array}{l}\text { Peanut butter and jelly } \\
\text { sandwich on white bread } \\
\text { with side of pretzels }\end{array}$ \\
\hline \multirow[t]{6}{*}{ Condiments } & Saltine crackers & Saltine crackers & Saltine crackers & Saltine crackers & Saltine crackers \\
\hline & Ketchup & Ketchup & Ketchup & Ketchup & Ketchup \\
\hline & Mustard & Mustard & Mustard & Mustard & Mustard \\
\hline & Mayonnaise & Mayonnaise & Mayonnaise & Mayonnaise & Mayonnaise \\
\hline & Butter & Butter & Butter & Butter & Butter \\
\hline & Margarine & Margarine & Margarine & Margarine & Margarine \\
\hline
\end{tabular}


sandwiches on white bread served with a corresponding side of pretzels; (ii) soup; (iii) main entrée option 1 with a corresponding side dish; (iv) main entrée option 2 with corresponding side dish; (v) fresh fruit (apples, oranges, bananas offered daily); (vi) yoghurt; (vii) dessert or canned fruit; and (viii) milk (skimmed, 1\% and Lactaid white milk only). The main entrée was provided by the head server to ensure standard portion sizes. The remaining items were pre-portioned in separate dishes by food-service staff in advance because vocational students participated in the lunch service.

Prior to the intervention, the menu was communicated to students through words and Picture Communication Symbols $^{\text {TM }}$ (Dynavox Mayer-Johnson LLC, Pittsburgh, PA, USA) for foods. Picture Communication Symbols are visual representations of concepts and ideas that reinforce meaning. They are used as an alternative method of communication for youth with cognitive impairments or communication disorders ${ }^{(29)}$. A placemat used as a tray liner depicted the lunch elements and included a picture highlighting dessert. The peanut butter and jelly sandwiches were available daily to accommodate students who had very limited food repertoires. Side dishes (i.e. pretzels and vegetable side dishes) were 'bundled' with the entrée. Students were permitted to refuse the side dish that was automatically plated with the entrée in accordance with National School Lunch Program rules for offer $v$. serve, but were not permitted to switch side dishes. A fruit bowl containing apples, oranges and bananas was kept behind the counter. Dessert was served on the eye-level counter by a vocational student. Canned fruit was offered on Tuesday and Friday, when dessert was not offered.

Students arrived to the dining hall by classroom, including the primary teacher and teaching assistants. Students had $30 \mathrm{~min}$ to choose and eat lunch. The lunch periods assigned to classrooms were staggered to avoid overcrowding. Teachers selected their own food from the serving line and ate lunch with their students to provide them with the support and supervision they required due to their cognitive, behavioural and physical challenges. No monetary transactions took place because student meals were included in yearly tuition.

\section{Intervention planning}

Adaptations to classic Smarter Lunchroom strategies were necessary due to physical and social factors within the lunchroom environment and the unique characteristics of the study population, including: cognitive disabilities (low literacy and comprehension, impairments in reasoning and decision making); sensory sensitivities (both auditory and oral); communication disorders; oral-motor impairments (all students are considered high risk for choking); and mobility limitations. Youth with I/DD, particularly those with autism spectrum disorder, may experience anxiety and exhibit disruptive behaviour in response to change and transition. Additionally, many students had communication challenges and language-based disabilities. Students were prepared for the impending changes through Social Stories ${ }^{\mathrm{TM}}$, videos, student lunch advisory committee activities and a $2 \mathrm{~d}$ pilot to practice data-collection procedures. Social Stories describe situations, relevant social cues and common responses in a specific format on the premise that an improved understanding of the situation will lead to the desired behavioural response ${ }^{(30)}$.

\section{Dining ball layout changes}

The intervention capitalized on environmental changes to enhance the students' experience of making choices in the serving line for all three weeks of the menu cycle (Fig. 1). The goal was to induce improvements in students' food choices through 'nudging' rather than menu changes. Communication of the menu choices was enhanced by supplementing the Picture Communication Symbols with real food photos. In our formative work, teachers described real food photos as the optimal visual aids because they were more accurate and descriptive compared with Picture Communication Symbols. For example, students were confused if the entree-sized salad on the lunch menu was taco salad with multiple toppings but the Picture Communication Symbol featured a plain lettuce salad. The placemat was revised to present a non-directive (no foods pictured) instruction for food placement on the tray.

Peanut butter and jelly sandwiches were moved to the back counter and made available only by request to encourage students to at least consider the two main entrée options. Fruit was moved to the beginning of the serving line. Apples, bananas and oranges were separated into attractive and easy-to-reach baskets to improve accessibility. An easy-to-eat fruit option (e.g. apple sauce) was available by request daily near the fresh fruit. The healthiest entrée (i.e. meeting the greatest amounts of the dietary targets) was placed earlier in line, followed by side dishes. A critical change was the unbundling of side dishes and entrées, made in response to formative research which indicated students were confused by the inability to change side dishes and our desire to support autonomous choice. Teachers were trained to support autonomous student choices in the serving area. Desserts were kept behind the counter, rather than serving them at eye level. Milk and yoghurt were not targeted for improvement because formative research suggested that almost all students selected dairy daily. The menu was altered in two instances. One menu change was to serve peanut butter and jelly sandwiches on wheat bread rather than white; a second change was to reduce the portion sizes of desserts to $75 \%$ of their original size. The two menu changes were a result of our community-engaged formative research; teachers unanimously asked for these two changes during the planning stage.

Activities to support the intervention included: (i) prompting by 'celebrity servers'; (ii) the creation of fruit and vegetable-inspired artwork for the dining hall; 


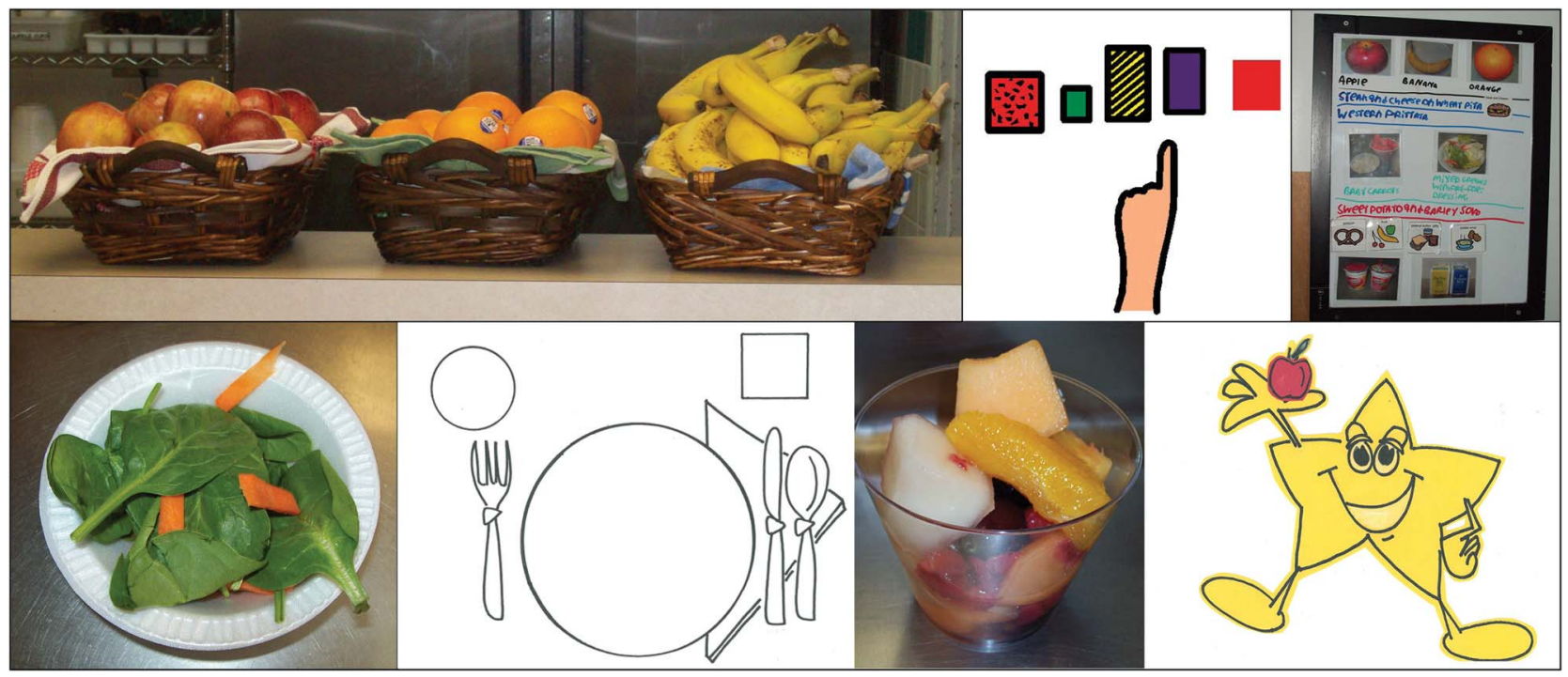

Fig. 1 (colour online) Intervention elements. From left to right: easy-to-reach fruit baskets, Picture Communication Symbol ${ }^{\mathrm{TM}}$ for 'choose', menu board featuring food photographs (top), baby spinach side dish, non-directive placemat, fruit salad side dish, intervention logo (bottom). ${ }^{\star}$ The Picture Communication Symbols C1981-2011 by Mayer-Johnson LLC. All Rights Reserved Worldwide. Used with permission

(iii) classroom-based taste-testing activities; and (iv) logonaming and branding activities. Fidelity to the layout changes was monitored on three non-consecutive days for the first four weeks of the intervention, followed by weekly observations in months 2 and 3. Specifically, vocational students who worked in the serving area required support to adjust to their new roles. We monitored the ability of students and staff to serve the food as delineated in the layout plan.

\section{Measures}

The digital photography of foods method ${ }^{(31,32)}$ was used to measure food selection and plate waste at lunch for five consecutive days (Monday through Friday) at baseline in February 2012 and five consecutive days (Monday through Friday) at follow-up in June 2012 on the same week of the menu cycle to allow for direct comparison. Digital photography methodology has been validated in school cafeteria settings in comparison to weighed and visual estimation of portion sizes ${ }^{(32)}$. Two camera stations were located near the exit of the serving area to capture selection and at the waste disposal station to capture plate waste. Trays were lined with a paper placemat that contained a unique identification to link selection and plate waste photos to the individual participants each day. Two angle $\left(41^{\circ}\right)$ and two aerial $(40 \mathrm{~cm}$ (16 in)) photographs were taken of each tray to assess selection and plate waste, for a total of four photographs per participant per day.

Portions of each available item were weighed in triplicate at baseline and follow-up to ensure no changes in serving sizes (with the exception of desserts) occurred. Standardized recipes and nutrient content of each available item were analysed by a registered dietitian (K.L.H.) using the Nutrition Data System for Research (NDSR; University of Minnesota, Minneapolis, MN, USA, 2011). NDSR was used to calculate servings of fruits, vegetables, whole grains and refined grains per each available item. NDSR food group servings were derived from the Nutrition Coordinating Center (NCC) Food Group Serving Count System, defined per the Dietary Guidelines for Americans 2005. All items, including side dishes, had the potential to contribute to the calculated servings. Each food was linked to macronutrient and micronutrient information from NDSR. Food selection and plate waste were estimated using a triple-screen computer set-up that simultaneously displayed photographs of the reference portion, food selection and plate waste. A trained research assistant coded selection as 'yes/no' of each available item followed by quantity, because for certain items, such as milk, participants were permitted to take more than one. Selection was verified by a registered dietitian when plate waste was coded.

Photographs of weighed standard reference portions were captured for all available items. A registered dietitian estimated consumption by comparing the plate waste photograph with the standard reference photograph. Consumption was coded on a five-point scale (0\%, $25 \%$, $50 \%, 75 \%, 100 \%$ ). Consumption estimates for fruits with cores and peels included the edible portion only. Gram weights were estimated from the plate waste photographs as follows: consumption estimates were entered and linked to the NDSR nutrient analyses based on gram weights of the reference portion. Servings of fruits, vegetables, whole grains and refined grains of each available item selected, wasted and consumed were calculated from 
the standardized recipes in NDSR. In addition to servings, counts of all available items selected and consumed were generated.

\section{Data analysis}

Three different analyses of the data were conducted. First, for the primary analysis, mixed linear regression models were used to evaluate mean changes in servings of fruits, vegetables, whole grains and refined grains selected, wasted and consumed with the individual participant as the unit of analysis. The models included two fixed within-participant factors that were crossed: visit (baseline $v$. follow-up) and day of the week. Random participant intercepts were used to induce the withinparticipant correlations. Day-to-day variability was assessed using a likelihood ratio test comparing the log-likelihood of full models that included the interaction terms with partial models with no interaction terms.

Second, the percentage of selected foods that were wasted was examined. Overall plate waste was assessed by calculating the percentage of total kilojoules and total gram weight of foods selected that were wasted. The plate waste of fruits and vegetables was assessed by calculating the percentage of the servings selected that were wasted. The mean percentage of plate waste (for total kilojoules, total gram weight and total fruit and vegetable servings) was calculated for each participant and averaged across all participants.

Third, Poisson regression was used to evaluate changes in item count of foods selected and consumed. Counts were used to examine the relative contribution of changes in selection of foods targeted in the intervention (i.e. whole fruit, canned fruit, vegetable side dishes, soup side dishes, entrée-sized salads, desserts, and peanut butter and jelly sandwiches) to the changes in servings of fruits, vegetables, whole grains and refined grains selected (expressed as a rate: per 100 student-trays). We used the same approach to examine the relative contribution of changes in consumption. Rates of milk and yoghurt selection and consumption were examined for potential unintended shifts away from these foods. All statistical analyses were conducted using SAS statistical software package version $9 \cdot 2 ; P$ values less than 0.05 were considered statistically significant.

\section{Results}

\section{Enrolment}

Fifty-one participants were enrolled in the research study. For each participant, a complete data record would contain twenty observations, consisting of selection and plate waste photos on each of five days at both baseline and follow-up. Dietary data were excluded from six participants with completely missing baseline or followup data (due to hospitalizations), from one participant who had no matching pre-post intervention days and from one participant who followed a gluten-free diet sent from home. These exclusions yielded a final sample size of forty-three participants. Of the 860 possible observations for the forty-three participants, 196 were missing (23\%) leaving a total of 664 observations (332 selection, 332 consumption) for the analyses. Reasons for missing data consisted of classroom field trips, illness, off-campus job locations and transient refusal to participate in data collection. Each day, one to three participants refused to participate in the pre or post photograph. The mean age of the participants in the analyses was $18 \cdot 3$ (SD $2 \cdot 5$ ) years (range 11-22 years); $51 \%$ were female; $72 \%$ were residential students; and $53 \%$ were enrolled in the education programme.

\section{Selection}

Daily mean kilojoules and mean gram weight of foods and beverages selected did not change over the study period (Table 2). Significant benefits of the intervention were observed for daily selection of whole grain and refined grain servings (Fig. 2(a)). Daily selection of whole grains increased by a mean of 0.44 servings (from 1.62 to 2.06 servings) and refined grains decreased by a mean of 0.33 servings (from 0.82 to 0.49 servings). Daily selection of fruit and vegetable servings did not change. Significant variability in daily mean serving changes was observed for vegetable selection (likelihood ratio test, $P<0 \cdot 001$ ) but was not significant for the selection of fruit $(P=0 \cdot 16)$, whole grains $(P=0 \cdot 05)$ and refined grains $(P=0 \cdot 07)$.

Rates of selection of whole fruit, canned fruit, vegetable side dishes, soup side dishes, entrée-sized salads, desserts, and peanut butter and jelly sandwiches are shown in Table 3. The rate of canned fruit selection more than doubled. No significant changes were observed in rates of whole fruit selection. Raw vegetable side dishes and soup side dishes were grouped together to examine the changes in rates of selection for all vegetable side dishes. The rate of selection of all vegetable side dishes did not change significantly from baseline to follow-up. Total vegetable side dishes were divided into raw vegetable sides and soup

Table 2 Daily mean kilojoules and mean gram weight of food selected and consumed, at baseline and follow-up, among students $(n 43)$ aged $11-22$ years with intellectual and developmental disabilities attending a residential school in Massachusetts, USA, March-June 2012

\begin{tabular}{lccccc}
\hline & \multicolumn{2}{c}{ Baseline } & & \multicolumn{2}{c}{ Follow-up } \\
\cline { 2 - 3 } \cline { 5 - 6 } & Mean & $95 \% \mathrm{Cl}$ & & Mean & $95 \% \mathrm{Cl}$ \\
\hline $\begin{array}{l}\text { Selection } \\
\quad \text { Kilojoules }\end{array}$ & 3636 & 3381,3895 & & 3707 & 3448,3962 \\
$\begin{array}{l}\text { Gram weight } \\
\text { Consumption }\end{array}$ & 784 & 696,873 & & 791 & 702,878 \\
$\quad$ Kilojoules & 3025 & 2757,3288 & & 3054 & 2787,3322 \\
$\quad$ Gram weight & 610 & 532,689 & & 637 & 558,716 \\
\hline
\end{tabular}




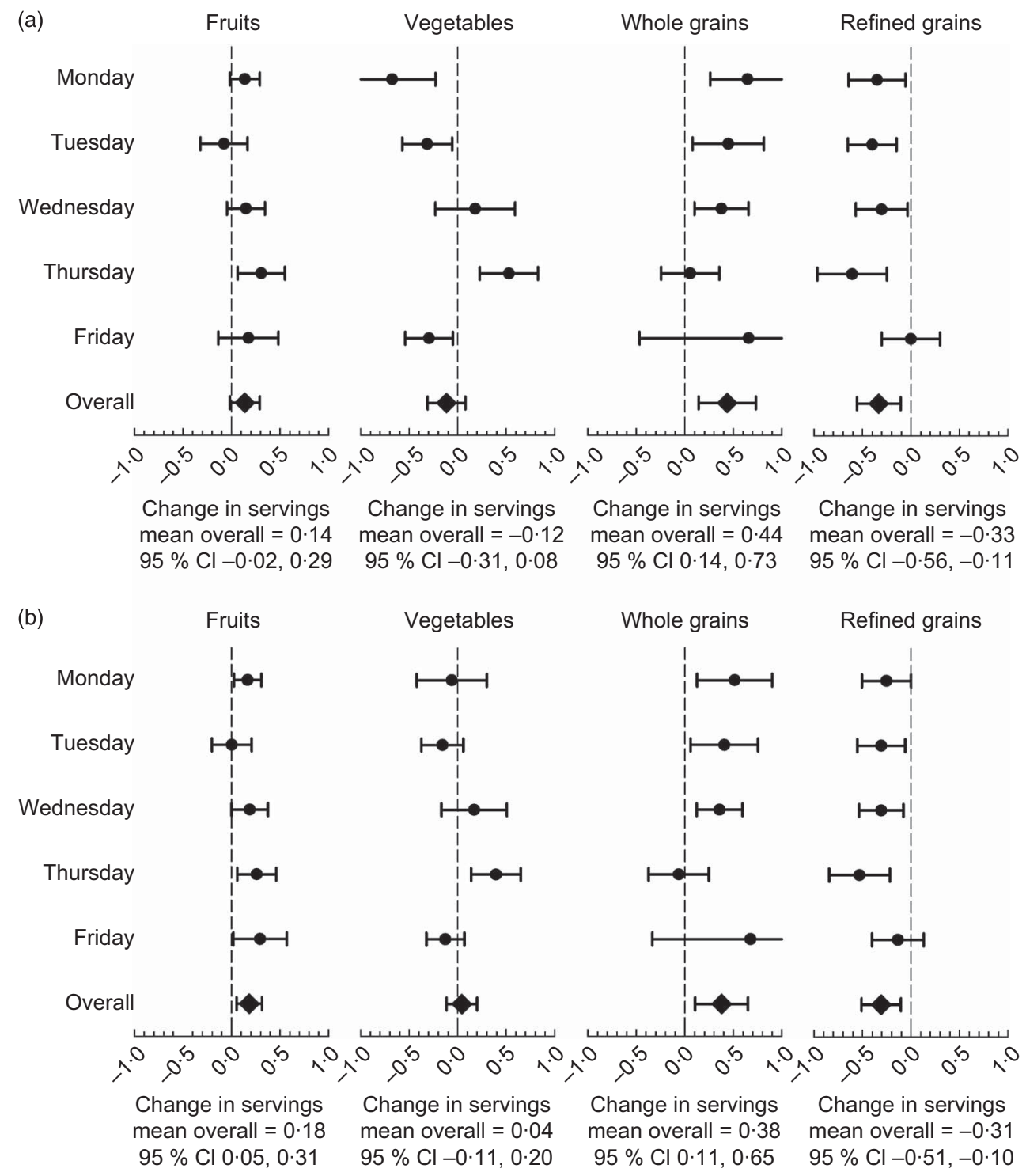

Fig. 2 Mean change (with 95\% confidence interval represented by horizontal bar) in daily servings of fruits, vegetables, whole grains and refined grains (a) selected and (b) consumed, from baseline to follow-up, by day of the week and overall, among students ( $n$ 43) aged 11-22 years with intellectual and developmental disabilities attending a residential school in Massachusetts, USA, March-June 2012

sides to determine whether the form of the vegetable impacted the rate of selection. The rate of soup selection increased significantly by $28 \%$, while the rate of selection of raw vegetable sides decreased significantly by $46 \%$. The rate of dessert selection did not change.

\section{Consumption}

Daily mean kilojoules and mean gram weight of foods and beverages consumed did not change over the study period (Table 2). Significant benefits of the intervention were observed for daily consumption of fruit, whole grain and refined grain servings (Fig. 2(b)). Daily consumption of fruits increased by a mean of $0 \cdot 18$ servings (from 0.39 to 0.57 servings), whole grains increased by a mean of 0.38 servings (from 1.44 to 1.83 servings) and refined grains decreased by a mean of 0.31 servings (from 0.68 to $0 \cdot 37$ servings). Daily vegetable servings consumed did not change. Significant variability in daily mean serving changes was observed for vegetable consumption (likelihood ratio test, $P=0 \cdot 008)$, but not for fruit $(P=0 \cdot 27)$, whole grain $(P=0 \cdot 05)$ and refined grain $(P=0 \cdot 28)$ consumption.

\section{Plate waste}

Participants at baseline wasted a mean of $17.5 \%$ of the total kilojoules selected and a mean of $21.4 \%$ of the total gram weight of foods and beverages selected. Overall plate waste did not change significantly over the intervention period $(17 \cdot 6 \%$ of the total kilojoules post and $19.5 \%$ of the total gram weight post). The change in the percentage of total kilojoules wasted differed significantly 
Table 3 Estimated differences in the rates of selection and consumption of menu items at baseline and follow-up among students ( $n$ 43) aged 11-22 years with intellectual and developmental disabilities attending a residential school in Massachusetts, USA, March-June 2012

\begin{tabular}{|c|c|c|c|c|c|c|c|}
\hline Measure & Time point & $\begin{array}{c}\text { Sample } \\
\text { observations } \\
\text { (student trays)* }^{*}\end{array}$ & $\begin{array}{l}\text { Baseline } \\
\text { rate (per } 100 \\
\text { student-trays) }\end{array}$ & $\begin{array}{l}\text { Follow-up } \\
\text { rate (per } 100 \\
\text { student-trays) }\end{array}$ & Rate ratio & $95 \% \mathrm{Cl}$ & $P$ value \\
\hline \multirow[t]{2}{*}{ Canned fruit } & Selection & 332 & $21 \cdot 69$ & $31 \cdot 32$ & $2 \cdot 37$ & $1 \cdot 11,5 \cdot 08$ & 0.03 \\
\hline & Consumption & 332 & $18 \cdot 07$ & $30 \cdot 72$ & $2 \cdot 55$ & $1 \cdot 18,5 \cdot 54$ & 0.02 \\
\hline \multirow[t]{2}{*}{ Whole fruit } & Selection & 332 & $28 \cdot 91$ & 34.93 & $1 \cdot 18$ & $0 \cdot 81,1 \cdot 71$ & 0.39 \\
\hline & Consumption & 332 & $25 \cdot 90$ & $30 \cdot 72$ & $1 \cdot 20$ & $0 \cdot 80,1 \cdot 80$ & 0.38 \\
\hline \multirow[t]{2}{*}{ All vegetable side dishes } & Selection & 332 & $97 \cdot 59$ & $92 \cdot 77$ & $1 \cdot 00$ & $0 \cdot 85,1 \cdot 18$ & 0.95 \\
\hline & Consumption & 332 & $77 \cdot 11$ & $84 \cdot 33$ & $1 \cdot 16$ & $0.95,1.41$ & 0.14 \\
\hline \multirow[t]{2}{*}{ Raw vegetable side dishes } & Selection & 332 & $53 \cdot 61$ & $36 \cdot 74$ & 0.54 & $0.41,0.70$ & $<0.001$ \\
\hline & Consumption & 332 & $38 \cdot 55$ & $33 \cdot 13$ & 0.68 & $0.49,0.95$ & 0.02 \\
\hline \multirow[t]{2}{*}{ Soup side dishes } & Selection & 332 & $43 \cdot 98$ & $56 \cdot 02$ & $1 \cdot 28$ & $1 \cdot 02,1 \cdot 60$ & 0.03 \\
\hline & Consumption & 332 & $38 \cdot 55$ & $51 \cdot 20$ & $1 \cdot 37$ & $1 \cdot 06,1 \cdot 76$ & 0.02 \\
\hline \multirow[t]{2}{*}{ Entrée-sized salads } & Selection & 204 & $7 \cdot 83$ & $5 \cdot 42$ & 0.75 & $0 \cdot 31,1 \cdot 82$ & 0.53 \\
\hline & Consumption & 204 & $7 \cdot 22$ & $5 \cdot 42$ & 0.95 & $0.35,2 \cdot 55$ & 0.92 \\
\hline \multirow[t]{2}{*}{ Desserts } & Selection & 140 & $34 \cdot 93$ & $27 \cdot 71$ & 0.87 & $0.70,1.08$ & $0 \cdot 20$ \\
\hline & Consumption & 140 & $34 \cdot 93$ & $25 \cdot 90$ & 0.81 & $0.65,1.02$ & 0.07 \\
\hline \multirow[t]{2}{*}{ Peanut butter and jelly sandwiches } & Selection & 332 & $13 \cdot 25$ & $15 \cdot 66$ & $1 \cdot 16$ & $0.53,2.51$ & 0.70 \\
\hline & Consumption & 332 & $13 \cdot 25$ & $15 \cdot 66$ & $1 \cdot 16$ & $0.53,2.51$ & 0.70 \\
\hline \multirow[t]{2}{*}{ Milk and yoghurt } & Selection & 332 & $149 \cdot 39$ & $140 \cdot 96$ & 0.94 & $0 \cdot 81,1 \cdot 10$ & 0.44 \\
\hline & Consumption & 332 & $138 \cdot 00$ & $133 \cdot 73$ & 0.96 & $0 \cdot 82,1 \cdot 13$ & 0.64 \\
\hline
\end{tabular}

*Entrée-sized salads and desserts not offered daily, resulting in differences in sample size.

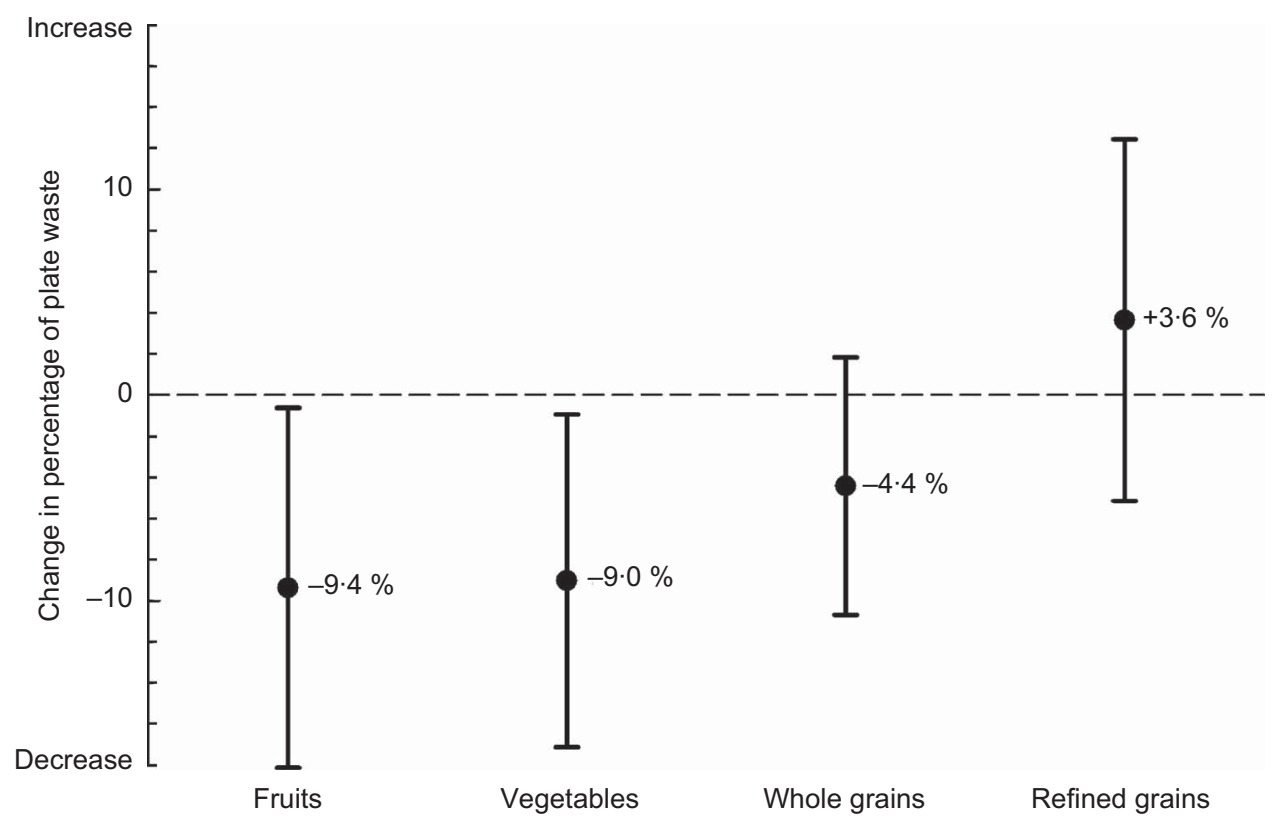

Fig. 3 Mean change (with $95 \%$ confidence interval represented by vertical bar) in percentage of fruit, vegetable, whole grain and refined grain servings wasted of those selected, from baseline to follow-up, among students $(n$ 43) aged 11-22 years with intellectual and developmental disabilities attending a residential school in Massachusetts, USA, March-June 2012

across days (likelihood ratio $P=0 \cdot 02$ ), but did not differ significantly for percentage gram weight wasted $(P=0 \cdot 15)$. Significant benefits of the intervention were observed for fruit and vegetable plate waste. The mean percentage of fruit servings wasted from those selected decreased by $9 \cdot 4 \%(P=0 \cdot 04)$ and the mean percentage of vegetable servings wasted from those selected decreased by $9 \cdot 0 \%(P=0 \cdot 03$; Fig. 3$)$. The percentage of fruit and vegetable servings wasted from those selected did not differ across days (fruit $P=0.97$, vegetables $P=0 \cdot 05)$.

\section{Discussion}

To our knowledge, the present study is the first to investigate food-environment intervention approaches based on behavioural economics and principles of behavioural 
science in a population of students with I/DD. Our findings are consistent with studies employing behavioural economic approaches in lunchroom environments among typically developing students. Verbal prompts from foodservice workers to encourage fruit selection resulted in significant improvements in selection and consumption of fruits at lunch among schoolchildren ${ }^{(33)}$. Peeling and slicing oranges to improve the accessibility of fruit increased the percentage of children selecting and consuming oranges in an elementary-school cafeteria ${ }^{(34)}$. When offered a choice between carrots or celery instead of a requirement to take them, a greater proportion of junior high students consumed their vegetable ${ }^{(35)}$. A Chef's Initiative intervention to improve the availability of healthy foods in Boston middle schools resulted in significant improvements in the proportion of students choosing whole grains and vegetables and the total amount of these foods consumed ${ }^{(36)}$.

The intervention resulted in shifts in the sources of kilojoules selected and consumed, with an overall improvement in diet composition, rather than a decrease in overall energy intake. We observed no overall increase in plate waste, nor did the intervention cause unintended shifts away from selecting and consuming healthy foods. These results suggest that the intervention was effective for improving dietary intake, but may not directly affect positive energy balance or obesity. The cumulative impact of these relatively small changes at one eating occasion translate to an increase of 1.0 fruit serving, an increase of $2 \cdot 2$ whole grain servings and a decrease of 1.7 refined grain servings for one individual over a $5 \mathrm{~d}$ school week. The observed improvement in whole grain consumption could be achieved by substituting half a slice of whole grain bread for half a bag of pretzels (refined grain) daily. The intervention resulted in a decrease in fruit and vegetable plate waste, supporting the hypothesis that students will consume a greater percentage of the fruit and vegetable side dishes when given the opportunity to make an autonomous choice. A reduction in fruit and vegetable plate waste could lead to significant cost savings for schools. The favourable impact was achieved through subtle 'nudge' mechanisms that preserve autonomous choice, were accepted by students, and carry a high potential for long-term sustainability due to the low implementation cost and potential for savings related to lower food waste.

Changes in the rates of particular menu items selected and consumed offer additional insights for the mechanisms by which changes in overall servings selected and consumed were achieved. Decreased rates of dessert selection and consumption, although non-significant, accounted for approximately $12 \%$ of the decrease in daily mean refined grain servings selected. Changing peanut butter and jelly sandwiches from white to wheat bread accounted for $30 \%$ of the increase in daily mean whole grain servings selected.

Observed shifts in selection towards canned fruits and soup suggest that processed forms of fruits and vegetables may be preferred over raw forms by students with I/DD. Although we observed a significant increase in the percentage of fruit servings consumed and rates of canned fruit selection and consumption, the magnitude of the behaviour change was not adequate to observe an overall increase in mean servings of fruit selected at the individual level. The power to detect these changes may have been limited by our small sample size.

Changes in vegetable servings selected should be interpreted with caution because the vegetable side dishes were automatically placed on trays at baseline, making it difficult to isolate true selection of these items at this time point. The unbundling of raw vegetable side dishes caused a shift towards soup side dishes. The soups contained 0.5 to 1 serving of vegetables per 6 ounce portion - less than the vegetable servings provided by raw vegetable side dishes. This may explain the increase in the percentage of vegetable sides consumed from those selected, but no significant increase in mean vegetable servings consumed.

The student population in the present study was heterogeneous with respect to primary and secondary diagnoses, medication use, cognitive ability and severity of behavioural and emotional challenges. The licensing policy of the school, designed to protect this vulnerable population, limited the ability to obtain additional information about the students beyond age and sex. Although it may have been beneficial to attempt to evaluate these and other potential modifying factors, the small sample size did not support the investigation of differential effects by studentlevel characteristics, even had they been available.

Two important limitations of the study were its small sample size and the lack of a control school to help rule out the potential influence of secular trends or events that may have occurred outside the study. To the best of our knowledge, the school did not implement any other changes in campus environments outside the dining hall that could impact food selection and eating habits at the lunch meal. None the less, findings should be replicated in a larger population and a comparison school, if possible.

Schools have been identified as the optimal venue to deliver nutrition interventions and policies for children and should support the inclusion of youth with I/DD. Interventions to improve dietary intake need to address barriers at the individual and environmental levels that are perceived or experienced by youth with I/DD and their caregivers ${ }^{(37)}$. In our experience, the communityengaged research process facilitated a broad and rich discussion of health promotion opportunities for youth with I/DD and led to an intervention that incorporated values of foremost importance to the school community. No students were excluded based on their disability and because the intervention did not rely on reasoning, those with significant cognitive impairments were not disadvantaged. Students readily adapted to layout changes, data collection procedures, and the switch of peanut butter 
and jelly sandwiches from white bread to wheat. There were no reports of behavioural problems.

Although the specific intervention elements may have limited generalizability, we believe the approach to the intervention design which focused on the process of developing adaptations based on formative research and engaging the school community is highly generalizable and makes an important contribution to the growing literature highlighting the need for the adaptation of evidence-based health promotion strategies ${ }^{(38)}$. Evidence from interventions with adults with intellectual disability support the involvement of caregivers in the research process as well as the consideration for the context of the lived disability experience ${ }^{(39)}$. The time required for the formative research and adaptation process was substantially greater compared with similar studies designed for typically developing students. A major impetus for a careful approach was to ensure student and teacher safety and to prevent unintentional cognitive or emotional stress.

\section{Conclusion}

A Smarter Lunchroom intervention, based on behavioural economics and adapted for students with I/DD, significantly increased whole grain selection and consumption, reduced refined grain selection and consumption, increased fruit consumption, and reduced fruit and vegetable plate waste. Results suggest that low-cost interventions that create environments in which the healthiest choice is the easiest choice hold great promise for improving the short-term food choices and dietary intake of this vulnerable population. Future studies are needed to evaluate whether dietary changes are maintained in the long term and if the effects are replicated in regular education settings.

\section{Acknowledgements}

Sources of funding: This study was funded by the Deborah Munroe Noonan Memorial Research Foundation. The Deborah Munroe Noonan Memorial Research Foundation had no role in the design, analysis or writing of this article. Conflict of interest: None. Ethics: This study was approved by the Tufts University Institutional Review Board. Authors' contributions: All authors contributed intellectually to the research aims, drafting and revising of the article, and gave final approval of the version to be published. K.L.H., L.G.B., S.C.F. and A.M. conducted the research. K.L.H. analysed the data and wrote the manuscript. M.E. assisted with the statistical analyses and interpretation of results. K.L.H. and A.M. had primary responsibility for the final content. Acknowledgements: The authors would like to thank the students at the Cardinal Cushing School for participating in the study. They gratefully acknowledge the contributions of the school staff and the Project Advisory Board to the design and implementation of the intervention.

\section{References}

1. Bandini L, Curtin C, Hamad C et al. (2005) Prevalence of overweight in children with developmental disorders in the continuous National Health and Nutrition Examination Survey (NHANES) 1999-2002. J Pediatr 146, 738-743.

2. Chen AY, Kim SE, Houtrow AJ et al. (2010) Prevalence of obesity among children with chronic conditions. Obesity (Silver Spring) 18, 210-213.

3. Curtin C, Anderson SE, Must A et al. (2010) The prevalence of obesity in children with autism: a secondary data analysis using nationally representative data from the National Survey of Children's Health. BMC Pediatr 10, 11.

4. Emerson E \& Robertson J (2010) Obesity in young children with intellectual disabilities or borderline intellectual functioning. Int J Pediatr Obes 5, 320-326.

5. Simeonsson RJ, McMillen JS \& Huntington GS (2002) Secondary conditions in children with disabilities: spina bifida as a case example. Ment Retard Dev Disabil Res Rev 8, 198-205.

6. Bandini L, Schoeller DA, Fukagawa NK et al. (1990) Body composition and energy expenditure in adolescents with cerebral palsy or myelodysplasia. Pediatr Res 29, 70-77.

7. Hurvitz EA, Green LB, Hornyak JE et al. (2008) Body mass index measures in children with cerebral palsy related to gross motor function classification: a clinic-based study. Am J Phys Med Rehabil 87, 395-403.

8. Luke A, Roizen NJ, Sutton M et al. (1994) Energy expenditure in children with Down syndrome: correcting metabolic rate for movement. J Pediatr 125, 829-838.

9. Bégarie J, Maïano C, Leconte P et al. (2013) The prevalence and determinants of overweight and obesity among French youths and adults with intellectual disabilities attending special education schools. Res Dev Disabil 34, 1417-1425.

10. Lin JD, Yen C, Li C et al. (2005) Patterns of obesity among children and adolescents with intellectual disabilties in Taiwan. J Appl Res Intellect Disabil 18, 123-129.

11. Stewart L, Van de Ven L, Katsarou V et al. (2009) High prevalence of obesity in ambulatory children and adolescents with intellectual disability. J Intellect Disabil Res $\mathbf{5 3}$, 882-886.

12. Takeuchi E (1994) Incidence of obesity among school children with mental retardation in Japan. Am J Ment Retard 99, 283-288.

13. Drum C, McClain MR, Horner-Johnson W et al. (2011) Health Disparities Chart Book on Disability and Racial and Ethnic Status in the United States. Concord, NH: University of New Hampshire, Institute on Disability.

14. Gibson JC, Temple VA, Anholt JP et al. (2011) Nutrition needs assessment of young Special Olympics participants. J Intellect Dev Disabil 36, 264-268.

15. Sharp WG, Berry RC, McCracken C et al. (2013) Feeding problems and nutrient intake in children with autism spectrum disorders: a meta-analysis and comprehensive review of the literature. J Autism Dev Disord 43, 2159-2173.

16. Twachtman-Reilly J, Amaral SC \& Zebrowski PP (2008) Addressing feeding disorders in children on the autism spectrum in school-based settings: physiological and behavioral issues. Lang Speech Hear Serv Sch 39, 261-272.

17. Evans EW, Must A, Anderson SE et al. (2012) Dietary patterns and body mass index in children with autism and typically developing children. Res Autism Spectr Disord 6, 399-405.

18. Yen C-F \& Lin J-D (2010) Factors for healthy food or lesshealthy food intake among Taiwanese adolescents with intellectual disabilities. Res Dev Disabil 31, 203-211.

19. Institute of Medicine (2004) Preventing Childhood Obesity: Health in Balance. Washington, DC: The National Academies Press. 
20. Minihan P, Fitch S \& Must A (2007) What does the epidemic of childhood obesity mean for children with special health care needs? J Law Med Ethics 35, 61-77.

21. Just DR \& Wansink B (2009) Smarter lunchrooms: using behavioral economics to improve meal selection. Choices 24, issue 3; available at http://www.choicesmagazine.org/ magazine/article.php?article $=87$

22. Rimmer JH (2002) Health promotion for individuals with disabilities. Dis Manage Health Outcomes 10, 337-343.

23. Cornell Center for Behavior Econcomics in Child Nutrition Programs (2012) Six guiding principles to improving eating behaviors. http://smarterlunchrooms.org/sites/default/ files/introduction_to_smarter_lunchrooms_6_principles_ powerpoint.pdf (accessed April 2013).

24. Hanks AS, Just DR \& Wansink B (2013) Smarter lunchrooms can address new school lunchroom guidelines and childhood obesity. J Pediatr 162, 867-869.

25. US Department of Agriculture, Food and Nutrition Service (2012) Nutrition Standards in the National School Lunch and School Breakfast Programs. 7 CFR Parts 210 and 220. Fed Reg 77, issue 17, 4088-4167.

26. Cook T \& Campbell D (1979) Quasi-Experimentation: Design and Analysis Issues for Field Studies. Boston, MA: Houghton Mifflin Company.

27. Boyle CA, Boulet S, Schieve LA et al. (2011) Trends in the prevalence of developmental disabilities in US children, 1997-2008. Pediatrics 127, 1034-1042.

28. Hubbard K, Bandini L, Folta SC, et al. (2012) Adaptation of smarter lunchroom design to the specific needs of children with intellectual and developmental disabilities: formative research and community collaboration. Presented at the American Public Health Association 140th Annual Meeting and Exposition, San Francisco, CA, USA, 27-31 October 2012.

29. Mayer-Johnson LLC (2013) Picture Communication Symbols. http://www.mayer-johnson.com/category/symbols-andphotos (accessed September 2013).
30. The Gray Center for Social Learning and Understanding (2013) What are Social Stories ${ }^{\mathrm{TM}}$ ? http://www thegraycenter.org/social-stories/what-are-social-stories (accessed June 2013).

31. Williamson DA, Allen HR, Martin PD et al. (2004) Digital photography: a new method for estimating food intake in cafeteria settings. Eat Weight Disord 9, 24-28.

32. Williamson DA, Allen HR, Martin PD et al. (2003) Comparison of digital photography to weighed and visual estimation of portion sizes. J Acad Nutr Diet 103, 1139-1145.

33. Schwartz MB (2007) The influence of a verbal prompt on school lunch fruit consumption: a pilot study. Int J Behav Nutr Phys Act 4, 6 .

34. Swanson M, Branscum A \& Nakayima PJ (2009) Promoting consumption of fruit in elementary school cafeterias. The effects of slicing apples and oranges. Appetite 53, 264-267.

35. Price JP \& Just DR (2009) Getting kids to eat their veggies. Presented at the International Association of Agricultural Economists 27th Triennial Conference, Beijing, China, 16-22 August 2009.

36. Cohen JF, Smit LA, Parker E et al. (2012) Long-term impact of a chef on school lunch consumption: findings from a 2 -year pilot study in Boston middle schools. J Acad Nutr Diet 112, 927-933.

37. Humphries K, Traci M \& Seekins T (2004) A preliminary assessment of the nutrition and food-system environment of adults with intellectual disabilitites living in supported arrangements in the community. Ecol Food Nutr 43, $517-532$.

38. Rimmer JH (2011) Promoting inclusive community-based obesity prevention programs for children and adolescents with disabilities: the why and how. Child Obes 7, 177-184.

39. Hamilton S, Hankey CA, Miller S et al. (2007) A review of weight loss interventions for adults with intellectual disabilities. Obes Rev 8, 339-345. 